\title{
Études/Inuit/Studies
}

\section{Identifying Pre-Dorset structural features on southern Baffin Island: Challenges and considerations for alternative sampling methods \\ Identification de structures prédorsétiennes en Terre de Baffin méridionale: méthodes alternatives d'échantillonnage}

\section{S. Brooke Milne}

Volume 27, numéro 1-2, 2003

Architecture paléoesquimaude

Palaeoeskimo Architecture

URI : https://id.erudit.org/iderudit/010796ar

DOI : https://doi.org/10.7202/010796ar

Aller au sommaire du numéro

Éditeur(s)

Association Inuksiutiit Katimajiit Inc.

ISSN

0701-1008 (imprimé)

1708-5268 (numérique)

Découvrir la revue

Citer cet article

Milne, S. B. (2003). Identifying Pre-Dorset structural features on southern Baffin Island: Challenges and considerations for alternative sampling methods. Études/Inuit/Studies, 27(1-2), 67-90. https://doi.org/10.7202/010796ar
Résumé de l'article

Cet article décrit une composante prédorsétienne isolée au site Tungatsivvik (KkDo-3) dans le sud de la Terre de Baffin. Afin de faciliter la reconnaissance d'autres occupations prédorsétiennes, nous proposons une analyse du microdébitage et des échantillonnages systèmatiques.
Tous droits réservés ㄷLa revue Études/Inuit/Studies, 2003
Ce document est protégé par la loi sur le droit d'auteur. L'utilisation des services d'Érudit (y compris la reproduction) est assujettie à sa politique d'utilisation que vous pouvez consulter en ligne.

https://apropos.erudit.org/fr/usagers/politique-dutilisation/ 


\title{
Identifying Pre-Dorset structural features on southern Baffin Island: Challenges and considerations for alternative sampling methods
}

\author{
S. Brooke Milne*
}

Résumé: Identification de structures prédorsétiennes en Terre de Baffin méridionale: méthodes alternatives d'échantillonnage

Cet article décrit une composante prédorsétienne isolée au site Tungatsivvik (KkDo-3) dans le sud de la Terre de Baffin. Afin de faciliter la reconnaissance d'autres occupations prédorsétiennes, nous proposons une analyse du microdébitage et des échantillonnages systèmatiques.

Abstract: Identifying Pre-Dorset structural features on southern Baffin Island: Challenges and considerations for alternative sampling methods

This paper describes an isolated Pre-Dorset component found at the Tungatsivvik (KkDo-3) site on southern Baffin Island. Micro-debitage analysis and systematic core sampling are proposed as a combined strategy to facilitate future investigations of Pre-Dorset occupations in this region.

\section{Introduction}

The coastal regions of southern Baffin Island are characterized by extensive rock outcrops, low-lying wetlands, and thick vegetation. Together, these factors present significant challenges to archaeologists investigating the Pre-Dorset occupation of this region. The rocky terrain limits the number of spots suitable for camping. As a result, many sites comprise multiple occupations, which frequently means that older PreDorset remains are disturbed or displaced by more recent cultural groups. High moisture levels and acidity in the vegetation combined with annual freeze-thaw cycles also act to destroy Pre-Dorset organic artifacts and faunal remains, making it difficult

Department of Anthropology, McMaster University, Hamilton (Ontario), Canada, L8S 4L9. sbrooke.milne@sympatico.ca 
to determine site seasonality. Furthermore, heavy vegetation can obscure the archaeological visibility of Pre-Dorset sites altogether.

On occasion, however, isolated surface finds do indicate the location of a subsurface Pre-Dorset site. In 1999, Robert Park found several pieces of debitage lying on the surface at the large multi-component Tungatsivvik site, which is located $10 \mathrm{~km}$ outside of Iqaluit. Upon further investigation, an isolated, undisturbed Pre-Dorset component was revealed. This part of the site is referred to as Area Q. While it has been known for some time that the Pre-Dorset lived at Tungatsivvik, an isolated component had never been found. In this paper, I describe the Area Q Pre-Dorset remains excavated in 1999. I then propose how a different line of evidence and an alternative sampling strategy could help alleviate some of the challenges archaeologists face when investigating Pre-Dorset sites on southern Baffin Island.

\section{Area Q, Tungatsivvik Site (KkDo-3)}

Tungatsivvik is situated on the eastern shore of Peterhead Inlet, not far from the head of Frobisher Bay (Figure 1). The Pre-Dorset, Dorset, Thule, and Inuit have all occupied the site and nearly 100 cultural features have been recorded. The most prominent of these are 16 Thule semi-subterranean winter houses located in the central part of the site. To date, most of the work conducted at Tungatsivvik has focused on these large structures; however, Pre-Dorset and Dorset artifacts have been recovered in secondary context from every excavated Thule house (Park 1998, 1999; Stenton and Rigby 1995: 50). As a result, we know the Palaeo-Eskimo occupation of the site is extensive.

Area $\mathrm{Q}$ is located just east of the main site proper and has a recorded elevation of $14.1 \mathrm{~m}$ above sea level (asl). Because of poor preservation conditions, no organic materials suitable for dating purposes were recovered from this component. However, given Area Q's elevation and its proximity to the Shaymark site, which is located at $12.2 \mathrm{~m}$ asl (Maxwell 1973) and has a corrected radiocarbon date of $3675 \pm 144$ B.P. (Arundale 1981), one can roughly estimate that the occupation at Area Q occurred relatively early on in the Pre-Dorset period (4225-2750 B.P.) (Maxwell 1976, 1985).

Area $\mathrm{Q}$ is approximately 25 to $50 \mathrm{~m}$ away from any other cultural deposits at Tungatsivvik. Because of the nature of the topography in the larger site area, pronounced differences in elevation of anywhere between 2 to $5 \mathrm{~m}$ also clearly separate Area Q from these later occupations (Figure 1). Simply stated, no evidence was found at Area $Q$ or in its immediate vicinity indicating the presence of any cultural occupation other than Pre-Dorset.

The ground cover surrounding Area Q consists of grass, moss, lichen, and loose gravel (Figure 2). There are also numerous boulder outcrops, which limits the amount of level surface area suitable for camping. Three chert flakes were found on the surface amidst these outcrops yet no other signs of occupation were visible because of the 


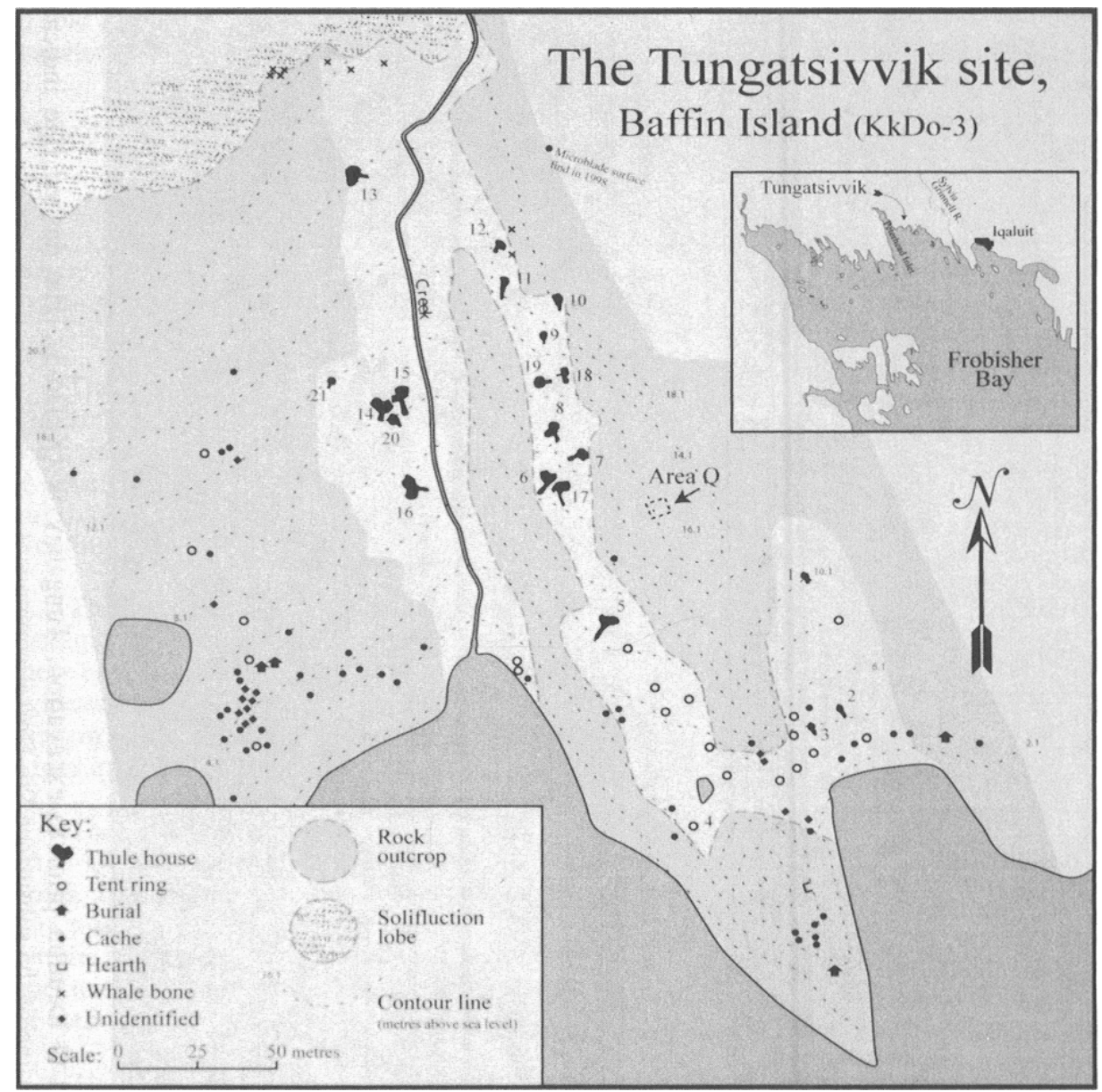

Figure 1. Tungatsivvik (KkDo-3) site, Frobisher Bay, southern Baffin Island, Nunavut (Park 1999) 


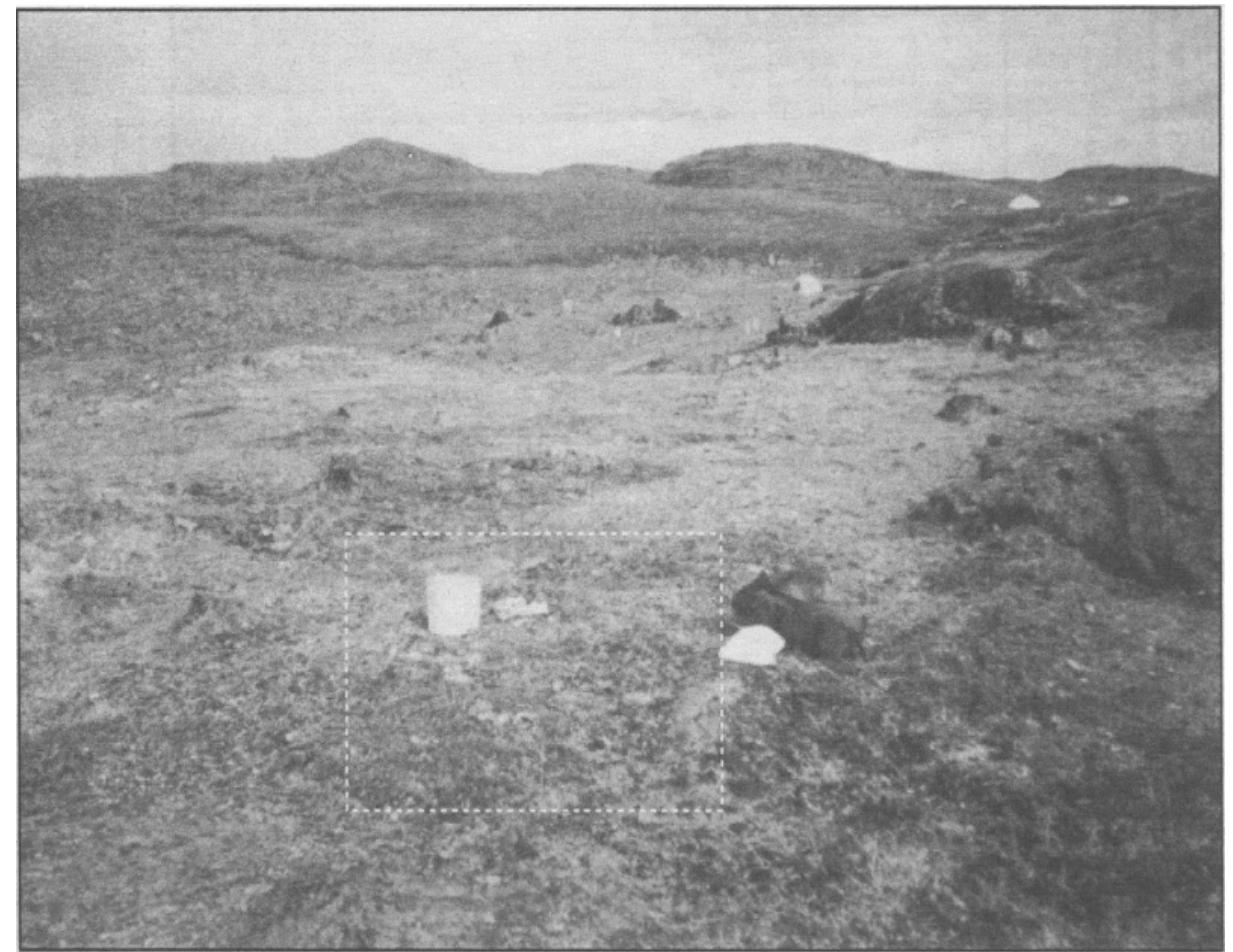

Figure 2. Area Q location prior to excavation, Tungatsivvik (KkDo-3). The dashed line indicates the approximate outline of the subsurface Pre-Dorset component 
vegetation cover. Preliminary investigations of Area Q yielded several diagnostic Pre-Dorset artifacts including burins, burin spalls, bifaces, and an endscraper (Figure 3). Based on these finds, excavations were expanded to include a total area of $5.25 \mathrm{~m}^{2}$ (Figure 4). This work uncovered the remains of an elliptical tent ring structure and an artifact assemblage comprising 314 flakes, 42 formal tools, and 7 informal tools (Table 1). While these excavated units were productive, further testing outside of them was not undertaken due to a lack of time.

Table 1. Frequencies of lithic artifacts from Area Q, Tungatsivvik (KkDo-3) site.

\begin{tabular}{|l|c|c|c|c|c|c|c|c|c|}
\hline & Debitage & Cores & $\begin{array}{l}\text { Informal } \\
\text { tools }\end{array}$ & Burins & Bifaces & Scrapers & $\begin{array}{l}\text { Burin } \\
\text { spalls }\end{array}$ & Microblades & $\begin{array}{l}\text { Artifact } \\
\text { Total }\end{array}$ \\
\hline $\begin{array}{l}\text { Area Q } \\
\text { KkDo-3) }\end{array}$ & 314 & 5 & 7 & 10 & 7 & 3 & 11 & 6 & 363 \\
\hline
\end{tabular}

The approximate dimensions for the tent ring structure are $2 \mathrm{~m} \times 2.5 \mathrm{~m}$ (Figure 5). The southern and northeast margins are defined by moderate to large size rocks while the northwest margin is defined, in part, by a bedrock outcrop. This outcrop is very flat in relief and does not rise above the original surface area. As such, it would not provide any kind of shelter for the site occupants nor would it pose any kind of obstacle for erecting a skin tent and/or securing its walls.

The entrance to the structure appears to be located along its southern margin, facing out towards Peterhead Inlet. Few artifacts were found in this immediate area and there is a gap here in the arrangement of perimeter rocks. While this is not conclusive evidence for an entrance, the general absence of artifacts and structural rocks along this margin combined with its orientation facing south towards the water is certainly suggestive.

The distribution of formal and informal artifacts, and debitage recovered from Area Q also suggests the interior of the structure was divided into separate activity areas. To the left of the entrance is a cluster of large and medium size rocks. Intuitively, this resembles a hearth; however, no faunal remains or burnt material were recovered within it. Despite this, concentrations of lithic debitage, burins, burin spalls, bifaces, and scrapers were found near these rocks indicating they were the focus of some kind of activity.

The location of this hearth-like feature in the southwest quadrant closely mirrors the location of such features in structures described by Dekin (1976) from southeastern Baffin Island. While the Area Q feature may appear somewhat close to what would have been the tent wall, it is important to remember the proposed perimeter of this structure is, like most efforts to delineate the outer walls of early Palaeo-Eskimo dwellings, an estimate. However, as Maxwell (1985) and McGhee (1996) describe, fires inside skin tent dwellings would have been controlled and monitored to regulate the accumulation of smoke. It also seems logical that care would be taken to prevent tent walls, among other items (i.e. clothing, bedding, floor cover), from catching fire. 


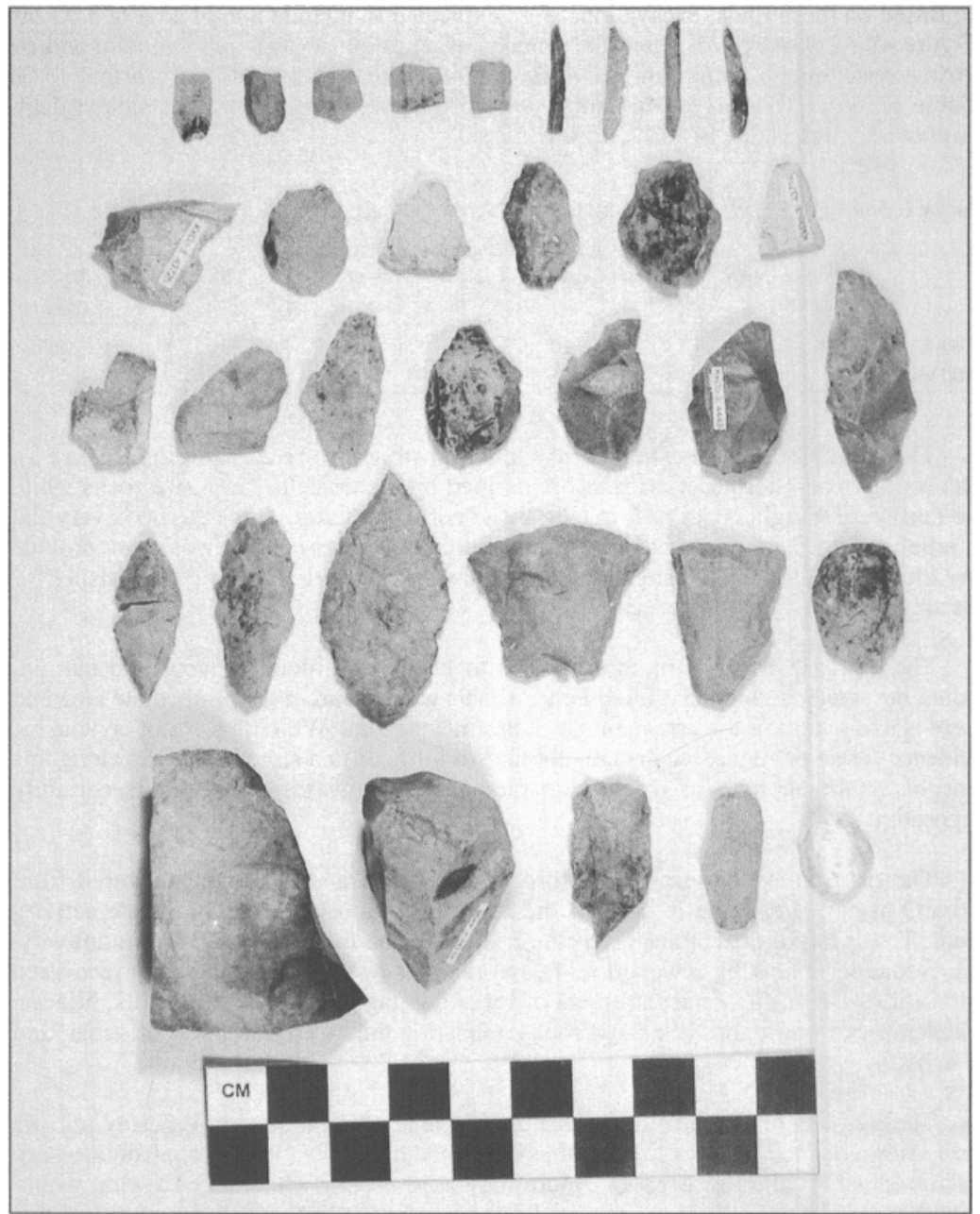

Figure 3. Sample of the Area Q artifacts including microblades, burins spalls, informal tools, burins, bifaces, endscrapers, and core fragments 


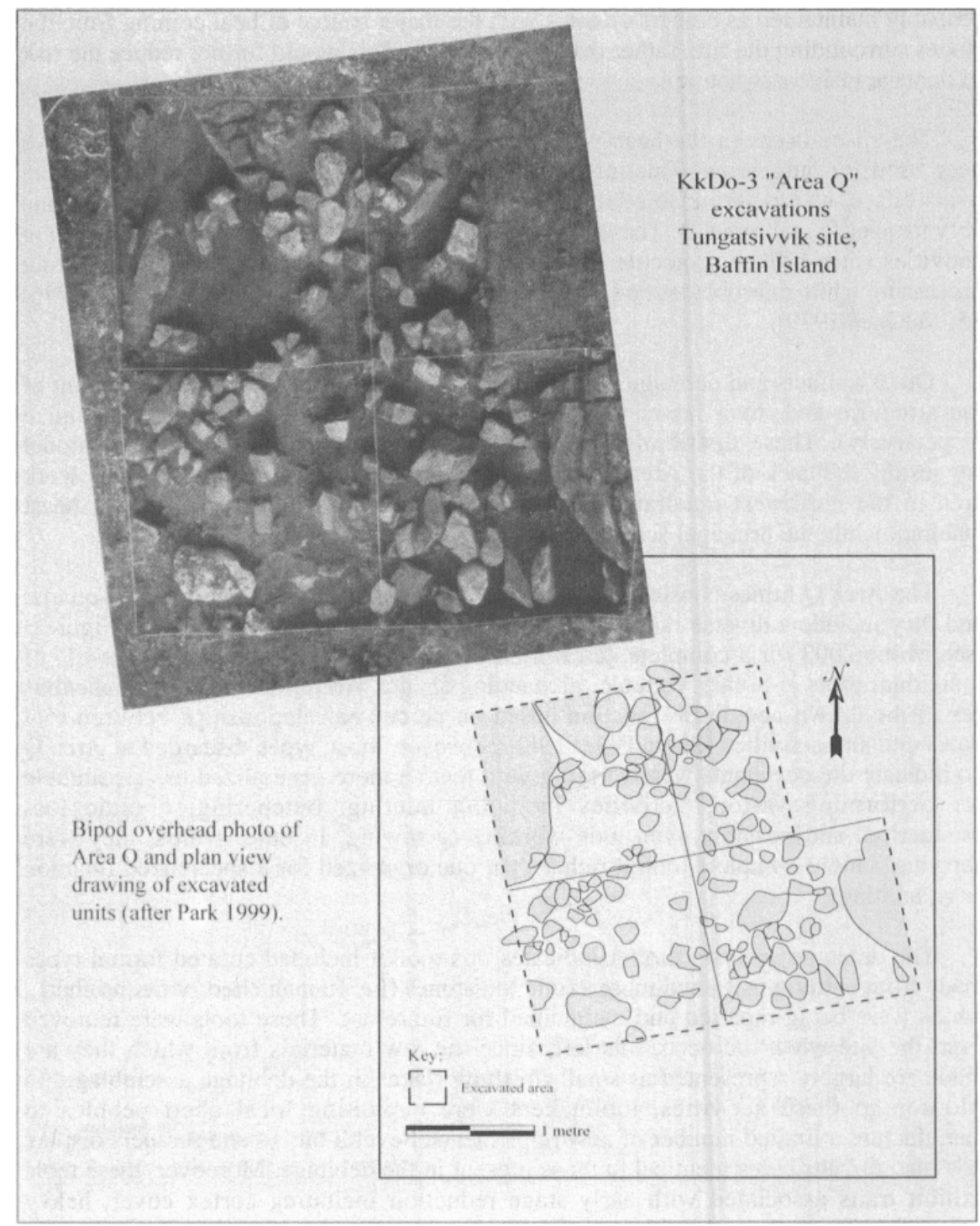

Figure 4. Bipod photo and plan view drawing of the excavated units at Area Q, the Tungatsivvik (KkDo-3) site 
Maxwell (1985: 63) speculates that once these internal fires burned down, they were probably maintained as embers or coals with the major source of heat coming from the stones surrounding the fire, rather than the fire itself. This would further reduce the risk of damage inside a structure.

The space between the hearth-like feature and the proposed entrance may have been used for butchering. This inference is supported by the recovery of a complete ovate biface, an indeterminable biface fragment, two microblade fragments, and some very meager faunal remains. These tool types are frequently associated with butchering activities since broken projectile points were removed from animal carcasses during processing while microblades and larger bifaces were used to cut them up (Dekin 1976: 85; McGhee 1979).

Other artifacts and debitage were found concentrated in the northwest quadrant of the structure and, to a lesser extent, in the northeast quadrant (Figures 5 and 6 respectively). These distribution patterns further conform to Dekin's 1976 model suggesting the back of the Area Q structure may have been divided into a lithic work area in the northwest quadrant and possibly a sleeping platform in the northeast quadrant while the principal activity area was located near the hearth-like feature.

The Area Q lithics consist predominantly of fine-grained chert and crystal-quartz, and they include a diverse range of functional types, which are illustrated in Figure 3 (see Milne 2003 for a complete description of this assemblage). Since the use-life of individual tools is highly variable, archaeologists are aware that simple conclusions cannot be drawn about site function based on perceived relationships between tool types and site activities (Shott 1997: 198). However, those types discarded at Area Q do indicate the occupants were carrying with them a more generalized toolkit suitable for performing various activities including hunting, butchering, organic tool production, and possibly even hide working or sewing. In other words, they were carrying a more complete toolkit rather than one organized for a specialized function (e.g., hunting).

The debitage analysis further indicates this toolkit included curated formal types made from better quality and more exotic toolstones (i.e. Ramah chert, vitreous chert), which were being repaired and maintained for future use. These tools were removed from the site when the occupants left, since the raw materials from which they are made are largely represented as small finishing flakes in the debitage assemblage. In addition to these activities, toolmakers were exploiting local chert pebbles to manufacture a limited number of new implements. Several burins and scrapers display raw material attributes identical to those present in the debitage. Moreover, these tools exhibit traits associated with early stage reduction including cortex cover, heavy percussion features, and evidence of battering associated with a bipolar reduction strategy. Given the small "package size" (Bradbury and Franklin 2000) of these local materials, a bipolar strategy provides toolmakers with an efficient method to quickly produce useable flakes and to extract some utility from otherwise inferior quality raw 


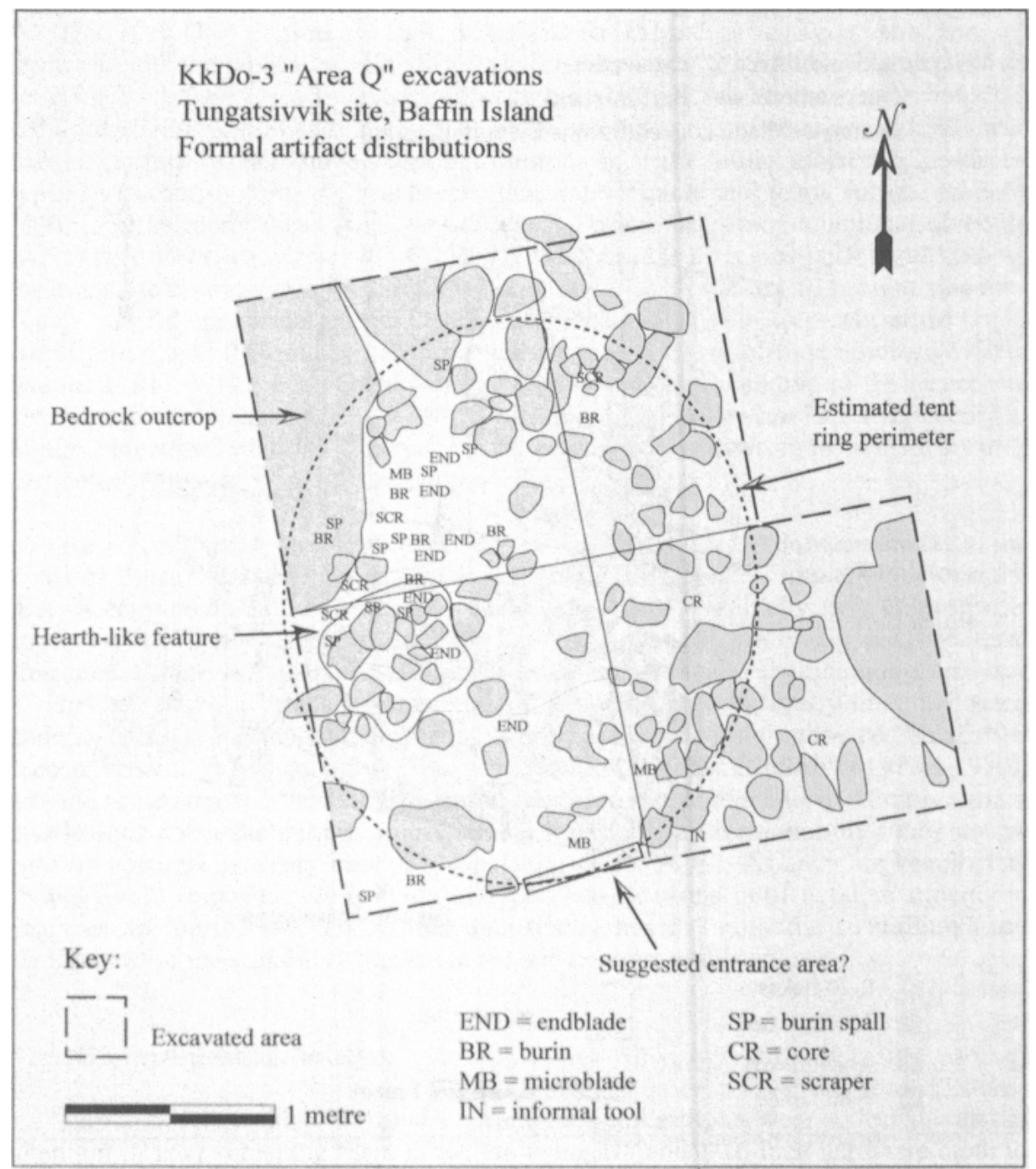

Figure 5. Recorded distributions of the Area Q artifacts, Tungatsivvik (KkDo-3) site (modified from Park 1999) 
KkDo-3 "Area Q" excavations

Tungatsivvik site, Baffin Island

Macro-debitage concentrations by unit quadrant

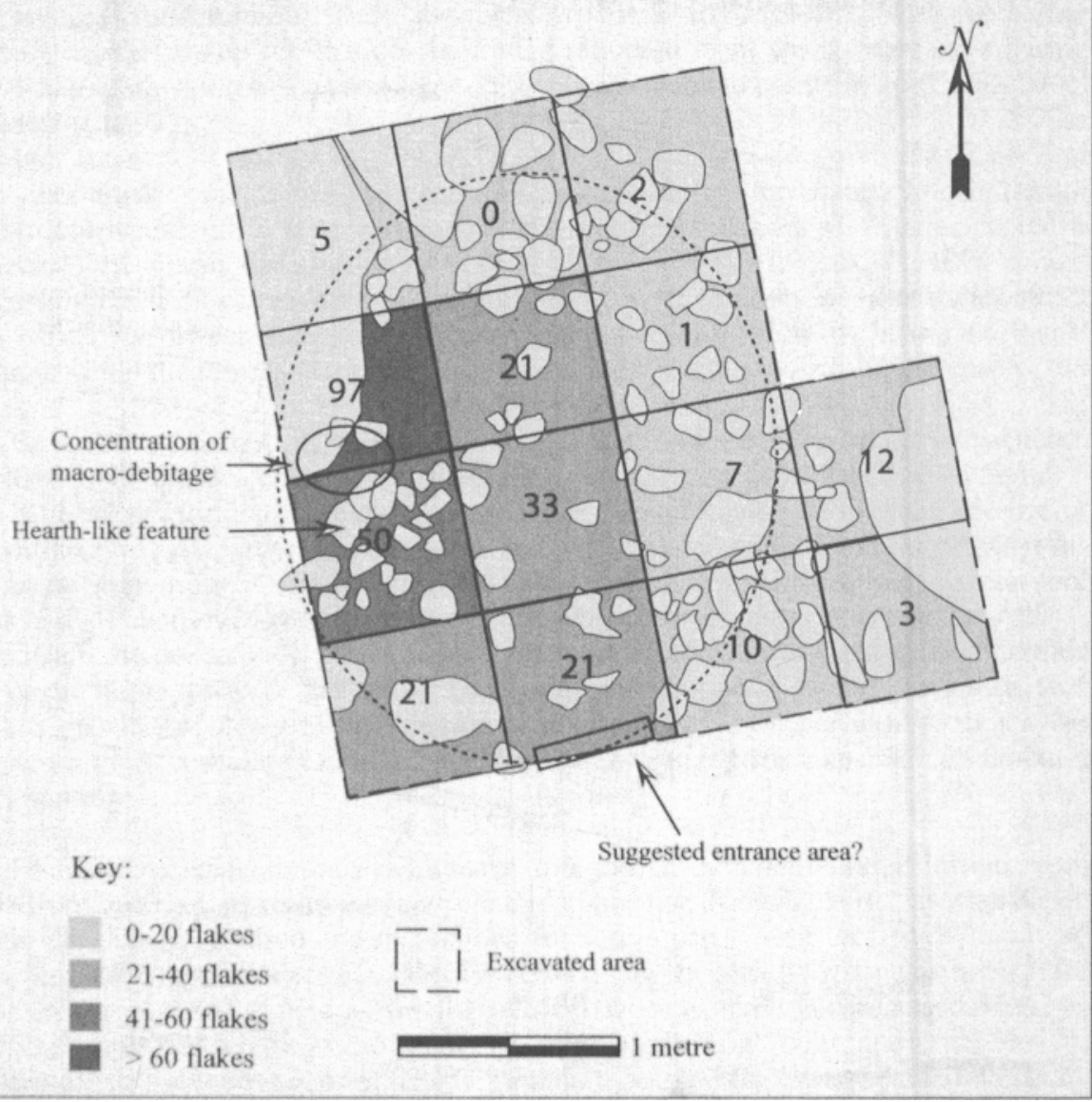

Figure 6. Distribution of macro-debitage flakes by unit, Area Q, Tungatsivvik (KkDo3) site (modified from Park 1999) 
materials (Goodyear 1993; Shott 1999). These bipolar flakes appear to have been expediently fashioned into these formal types for immediate use during the site's occupation after which, they were abandoned.

Had Area Q been used as a specialized site for hunting or resource extraction, the lithic assemblage would be very different. In instances when hunters are tracking or scouting for game, most tool reduction activities are undertaken to reduce boredom (Binford 1978b: 330). Consequently, debitage assemblages recovered from these sites consist largely of late stage reduction debris since the lithic tools being worked typically comprise curated formal types that are complete and ready for use (Nelson 1991). Furthermore, these types tend to exhibit a low degree of functional diversity (Andrefsky 1998; Chatters 1987; Nelson 1991) because activities performed at these locations are task specific. Finally, dwelling structures would not be present since the occupants of these special purpose sites usually include only one segment of the larger social group, and they rarely stay for any appreciable length of time (Binford 1978b; Nelson 1991). When one considers the location of Area Q relative to the larger site area, it is by no means an ideal spot for tracking game. There are locations nearby at higher elevations that could provide better vantage points from which to do this, particularly if the occupants were hunting caribou.

Based on the functional diversity of the formal types in the Area Q toolkit, the kinds of lithic reduction present, the spatial patterning of these materials within the described structure, and the location of this site, it is highly unlikely Area Q represents anything but a residential occupation. It should be noted that I use the term "residential" here with some hesitation since few technological and functional analyses of Pre-Dorset site remains have been conducted, thus we presently have a limited understanding of the range of site types used by this culture during the course of their seasonal round. While functional site models, most notably Binford's (1978a, 1980), provide some heuristic value for interpreting archaeological remains, they imply certain conclusions about the culture processes that led to a site's formation that may not be entirely accurate in every case (Nelson 1991; Odell 1994). As such, archaeologists should avoid imposing these kinds of type classifications until detailed functional analyses are performed. To do this uncritically has the potential to diminish the significance of the variability present in the site remains of this culture.

\section{Area Q micro-debitage analysis}

During the excavation of Area Q, several bulk soil samples were collected with the intention of later screening them in the lab using 1/8 and 1/16-inch hardware cloth to recover small size lithic debitage associated with tool resharpening and rejuvenation activities (see Baumler and Downum 1989; Towner and Warburton 1990). Given the size of these small diagnostic flakes, they easily pass through standard 1/4-inch screens resulting in a potentially significant loss of information during excavation. The collection of these soil samples did not follow any systematic method. They are simply random "grab" samples (Orton 2000) taken from areas where lithic debitage 
concentrations were high and where small size debitage resulting from these reduction activities was inferred likely to be.

Four years later, while studying Area Q as part of a larger research project (see Milne 2003), I realized these soil samples could also be used for another purpose: micro-debitage analysis. Micro-debitage is defined as "particles less than $1 \mathrm{~mm}$ in maximum dimension resulting from deliberate lithic reduction" (Fladmark 1982: 205). Baumler and Downum (1989: 105) note that particles slightly larger than those described by Fladmark (i.e. 1-2 mm) should also be considered microscopic. Under magnification, these particles appear highly angular, translucent or transparent, and they display some diagnostic attributes associated with conchoidal fracture (Fladmark 1982: 209). These tiny flakes are produced in large quantities during flint knapping episodes and they form a powder-like dust that settles both on the individual knapper and the immediate area in which they are working. Even experienced contemporary flint workers remark that this dust gets on everything from furniture in the room to their own skin and clothes. Vance (1987: 58) describes micro-debitage as lithic "sawdust" and notes it is formed by a specific activity and is deposited where that activity takes place. Because of its size, micro-debitage is not likely to be cleaned away or removed and consequently, it permeates site matrices and acts as a permanent sedimentary record of past cultural activity (Fladmark 1982: 208).

My objectives for conducting a micro-debitage analysis on the soil from Area $\mathrm{Q}$ were simple: I wanted to see if it was present in this Pre-Dorset component and if it was readily identifiable. Each of the bulk soil samples was screened using a set of standardized mesh sizes and all soil smaller than $1 \mathrm{~mm}$ was retained. I removed organic particles by immersing the soil in a soapy solution. Fine particles floated to the top and were easily removed (see Hull 1987: 775; Vance 1987: 58). The soil was then dried and split into smaller random samples using a device known as a two-way soil sample splitter. This device consists of a series of equally numbered and evenly spaced slots that randomly divides a sample. The soil is poured through, divided, and collected in two separate bins. Large samples can be quickly, efficiently, and objectively divided until the required amount is obtained. Ten samples weighing between 0.2 and 0.3 grams were drawn from each of the original bulk soil samples for analysis. They were each examined using a stereoscopic microscope at 40x, 50x, and 60x magnification.

Figure 7 illustrates an example of the micro-debitage flakes recovered from Area Q. They include quartz crystal and chert specimens, and their flat, angular appearance contrasts sharply from the natural sand grains in the soil making these flakes easily identifiable. These raw materials are identical to those recorded in the macro-debitage assemblage. Even though this micro-debitage analysis is exploratory, the information it provides about the Area Q structure is important. The soil sample taken from the area near the hearth-like feature yielded the most consistent amounts of micro-debitage. The other samples, which were collected from the proposed butchering area near the entrance and the sleeping platform in the structure's northeast quadrant, yielded comparatively fewer particles. This distribution is consistent with the frequencies of macro-debitage recorded in these areas, further suggesting reduction activities were more localized within the interior of the Area Q structure. 


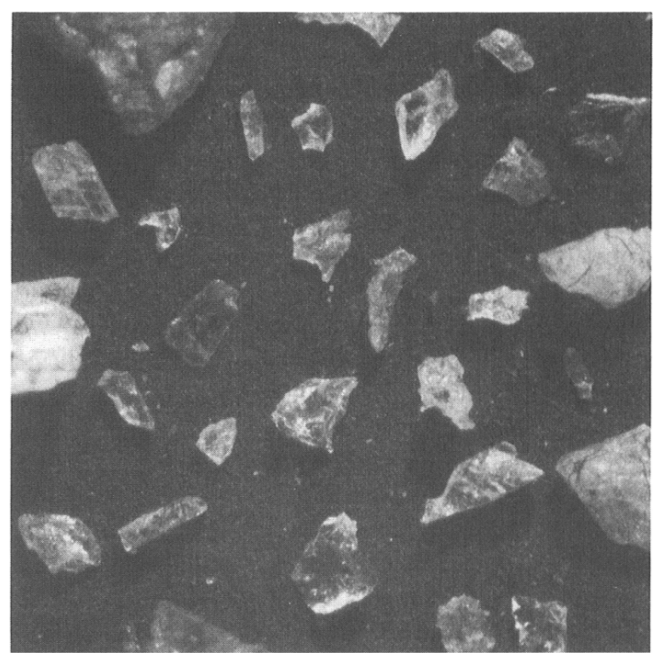

Figure 7. Area Q micro-debitage sample including chert and crystal-quartz specimens (60x magnification)

The actual numbers of micro-debitage flakes identified in each sample were not tallied since the objectives of this preliminary analysis were principally focused on identifying the existence of this line of evidence in an Arctic context. Moreover, since the bulk samples were collected without specific controls recording their precise location, the numbers could not be used to define the absolute boundaries of specific activity areas. Despite this, however, the recovery of micro-debitage in Area Q does indicate lithic reduction occurred within the structure and that these activities were concentrated in the vicinity of the hearth-like feature.

\section{Interpretive potential of micro-debitage}

Because the Pre-Dorset, and other Palaeo-Eskimo groups, utilized a chipped stone technology, micro-debitage analysis has great interpretive potential in Arctic research since archaeologists can be certain it is present in sites where lithic reduction occurred. Soil samples containing micro-debitage can be easily collected from these sites using a coring device or a trowel, and the size of these samples needs not be large. Average estimates indicate that for every 10,000 sand grains, one can expect to find between 0 to 100 micro-debitage flakes (Vance 1987: 58) and considering a 10,000 sand grain sample weighs only 0.23 grams (Hull 1987: 775), a lot of samples can be collected, shipped, and processed for micro-debitage with minimal expense. Collecting information from a site using samples such as these is ideal for Arctic research given the logistical constraints faced on most projects and the high cost of shipping material in the North. 


\section{Locating structural features and activity areas using micro-debitage analysis}

The information derived from micro-debitage analysis can be used to mitigate some of the challenges faced by archaeologists investigating Pre-Dorset sites on southern Baffin Island. For instance, in multi-component occupations, Pre-Dorset tent rings are frequently dismantled or disturbed by later groups who use the perimeter rocks to construct new features. This makes it difficult to verify if a tent ring was actually present since it may be only partially visible on the surface, if at all. Microdebitage can be used to confirm the existence of a structure, provided lithic reduction activities occurred inside it. In cases where a structure's exterior walls are incomplete, micro-debitage can even be used to help define where the walls once existed since the distribution of flakes would be localized within their boundaries (see Fladmark 1982: 217).

Micro-debitage is also well suited for investigating activity area use within structures (e.g., Hull 1987; Metcalf and Heath 1990; Oetelaar 2000; Rosen 1989). Internal structural features, such as mid-passages and box hearths, are conspicuously absent from Pre-Dorset sites on southern Baffin Island. Understanding spatial use without the presence of these kinds of features can be difficult since they provide important clues about the location of discrete spatial zones where activities like cooking, sleeping, and tool manufacture occurred (McGhee 1979; Stenton and Park 1998). Micro-debitage can be used to isolate activity areas within Pre-Dorset tent ring structures even when internal structural features are absent. One can distinguish areas of primary lithic reduction, tool finishing, and refuse deposition by examining the proportionate distributions of micro-debitage (see Hull 1987). One can also infer the location of non-lithic activity zones since micro-debitage will be noticeably absent (see Metcalf and Heath 1990).

Micro-debitage is invaluable for activity area analysis because the information it provides about the use of space is not dependent on the preservation of organic artifacts like needles and harpoon heads. Furthermore, micro-debitage is less likely to be displaced through post-depositional processes so the integrity of an activity area is more likely to be preserved (Oetelaar 2000: 52). This is especially critical when investigating questions about gendered uses of space and human agency (see Oetelaar 2000).

\section{Site verification using micro-debitage}

Micro-debitage is also useful for site verification purposes. Frequently, Pre-Dorset features are obscured by heavy vegetation cover making it virtually impossible to know if a site is present. Sometimes, the first indication a Pre-Dorset component exists at a site is when diagnostic lithic artifacts are found unexpectedly during the excavation of a more recent structure, such as a Thule winter house (e.g., Milne 1997; Park 1997, 1998). Attempts to locate the source of these artifacts are not always successful since looking for an obscured Pre-Dorset occupation at a large multi-component site, like Tungatsivvik, can make one feel as though looking for a needle in a haystack. 
However, if a systematic core sampling strategy were used to collect soil samples from around a site (e.g., Cannon 2000), micro-debitage analysis could pinpoint the location of an earlier component, especially if knapping activities were pursued in open-air locations. Micro-debitage is susceptible to wind displacement because of its microscopic size and a single reduction episode undertaken in an exposed location can leave a micro-debitage "signature" over a large surface area, making it more likely to be encountered during site sampling (Fladmark 1982: 208). This is not to say that micro-debitage can be simply blown away by the wind without a trace; rather, its distribution within a site simply becomes more diffuse covering a much larger area.

If a grid system is used, cores can be taken from individual units and examined for traces of micro-debitage. Those units yielding high concentrations will indicate the presence of site activity areas and features while those samples with much lower concentrations can be used to define the areal extent of a site or spatial gaps between occupations. This kind of sampling strategy is more efficient than test pitting and it allows for a much larger area to be investigated in a relatively short period of time. Furthermore, coring is less invasive than test pitting and more likely to yield valuable information. Identifying areas with the greatest information potential prior to wide scale excavation helps to focus research more effectively.

\section{Determining site seasonality using micro-debitage analysis}

Finally, micro-debitage analysis can be used to help resolve issues concerning PreDorset site seasonality. Sites from southern Baffin Island seldom have good organic preservation and as a result, the season in which a site was occupied is generally unknown. If a dwelling structure is identified, soil samples can be taken from both inside and outside areas. Concentrations of micro-debitage in these samples can be examined to determine where lithic tools were being worked. For warm weather occupations, one would expect tools to be worked outside where there is ample space and light, and where game could be easily scouted. If this scenario were true, microdebitage would be found in samples taken from outside the structure. These concentrations would likely be lower because of wind displacement; however, they would be present in more samples spanning a larger surface area. Micro-debitage would also likely be found in the dwelling since periods of inclement weather or insects would lead people to pursue activities inside. People may also have simply wanted to work inside.

For cold weather occupations, one would expect lithic activities to occur inside, since the cold outside would affect dexterity, reducing one's ability to fashion or repair a tool. Adequate light may have been an issue leading individuals to work inside as well. Tool making is also a social activity (see Dobres 1995; Sinclair 2000) and conceivably, individuals would gather together inside a dwelling to plan hunting strategies, manufacture and repair tools, and to socialize, especially during the winter. If this scenario were true, one would expect to find localized concentrations of microdebitage marking the presence of specific activity areas inside the confines of a tent ring structure. Micro-debitage would be effectively absent from soil samples taken 
outside since the walls of a skin tent would prevent any displacement beyond the interior area.

Even if skins covered the tent floor we can still expect to find evidence of microdebitage within the interior of a winter structure. Because micro-debitage settles like a dust on the flint knapper and the immediate area where they are working, we can expect micro-debitage to have accumulated among the seams of the skin floor and along the edges of the interior where the floor meets the tent wall. In these instances, concentrations of micro-debitage would be even more localized; however, their distributions would give a very accurate estimate of the size and dimensions of the dwelling structure inside which these activities took place.

Micro-debitage could even be used to determine if the walls of the tent were rolled inwards or outwards. If they were rolled inwards, the rocks holding down the edge of the tent would be pushed further into the middle of the structure when it was dismantled. As such, the rocks would come to rest on areas of the living floor where micro-debitage deposition occurred during occupation. Beneath these rocks traces of micro-debitage would be preserved, indicating the original dimensions of the structure were larger than they appear at the time of excavation. If the rocks were rolled outwards, there would be no micro-debitage settled beneath them since they would not have been exposed to any dust from knapping activities during the occupation and the wall of the tent would prevent its displacement beyond the interior.

By comparing the relative distributions of micro-debitage across a site area, one can still interpret site seasonality even when the location of structural features is unknown. If tent rings have been disturbed or they are simply not visible, concentrations of micro-debitage obtained through systematic core sampling can be studied to isolate the locations of activity areas and to determine whether or not they were bounded within the confines of a structural feature. While these scenarios are speculative at this point, they could be easily tested in the field.

\section{Caveats to consider}

While this discussion on the potential contributions micro-debitage analysis can make to research efforts focusing on the Pre-Dorset culture is very positive, this method is by no means a panacea. There are several caveats that should be considered when using this line of evidence to delineate the location of dwellings and to understand spatial use within them. These principally include length of occupation, the clearing of refuse during an occupation, and the reoccupation of dwelling structures over time.

It goes without saying that the longer a site is occupied, the greater the accumulation of debris resulting as a byproduct of individual actions. In instances where sites are occupied long enough to accumulate substantial quantities of debris, the occupants will remove it or clean it away (e.g., Binford 1978b; Hayden and Cannon 1983). This invariably results in the secondary deposition of material remains in a 
location separate from the one in which they were made and/or used (Metcalf and Heath 1990: 781). In sites where cleaning is consistently performed, archaeologists can expect to find little primary refuse of notable size (i.e. that can be seen with the "naked eye"). But micro-refuse (i.e. plant remains, bone splinters/fragments, micro-debitage) is less likely to be cleaned away and thus remains in the occupation area as primary refuse (Metcalf and Heath 1990: 782; Oetelaar 2000: 52). Despite this, however, the method used to clean an area will indeed affect the post-depositional distribution of micro-refuse. For example, if the remains of a hearth are scooped or chunked out for disposal, micro-refuse that accumulated in and around the fire can be entirely removed from its primary context resulting in the secondary deposition of micro-refuse outside of a structure (Simms and Heath 1990). If the occupants sweep the floors on which these particles have come to rest, the particles might not be removed in their entirety but the boundaries separating where the activities resulting in their production occurred from those areas where they did not will certainly be "smudged" (see Metcalf and Heath 1990). In both instances, the identification of micro-refuse in primary and secondary deposits can create confusion for archaeologists who aim to use this line of evidence to reconstruct spatial use, since it may not necessarily indicate the exact location of discrete activity areas. It can, however, still provide useful insights on cultural site formation processes, including cleaning behaviours and refuse disposal (Metcalf and Heath 1990; Simms and Heath 1990).

The intensity and frequency of reoccupation at a site can also complicate efforts to use micro-debitage analysis to understand spatial use within dwelling structures, particularly when multiple activities are carried out within the same confined area. Ethnoarchaeological (e.g., Binford 1978a; Janes 1989) and archaeological (e.g., Stenton and Park 1994) studies have documented the reuse of dwelling structures over time and note that admixture between occupation layers can and does occur. This "mixing" can make it extremely difficult to separate discrete living floors where microrefuse is preserved. Thus, activity areas become superimposed upon one another.

While these points are important to consider, they relate to cultural site formation processes that may not be entirely relevant to Pre-Dorset and other early PalaeoEskimo sites. At present, we know little about the rigidity of spatial use within early Palaeo-Eskimo structures, especially as it relates to gendered segregated areas (Bonesteel 2003). However, based on McGhee's (1979) early study on this issue, archaeologists infer the use of space was, more or less, rigidly maintained in these structures based on the distribution of certain formal artifact types. If this were the case, there would be little to no "smudging" between activity areas in residential sites. Similarly, there is little published information on Palaeo-Eskimo patterns of refuse disposal or cleaning activities. We do not know if structures and other features were cleaned, how it was done, and how frequently it occurred. This kind of information does exist for later cultural occupations in the Arctic (e.g., Park 2001; Stenton 2001; Stenton and Park 1994) but such systematic studies have yet to be conducted for the early Palaeo-Eskimo period.

Most early Palaeo-Eskimo structures are inferred to have been occupied for relatively short periods of time given the high degree of mobility practiced by these 
peoples (Maxwell 1985; McGhee 1990: 31). Thus the accumulation of refuse in these structures would be reduced, as would the need to clean it out. Furthermore, there is little indication that these cultures reoccupied the exactly same dwelling structures over time like patterns observed among prehistoric tipi rings in the Canadian Subarctic (e.g., Janes 1989). Certainly, site areas were reoccupied (e.g., McGhee 1979; Ramsden and Murray 1995) and structural rocks were removed from old dwellings to be incorporated into new dwellings (e.g., Møbjerg 1998: 104). But there are few published examples from the Arctic of actual early Palaeo-Eskimo structures being cleaned out and/or reused (e.g., Grønnow 1994). In fact, McGhee (1990: 32) speculates the early PaleoEskimos were reluctant to do this for cosmological reasons.

I am not ruling out the possibility that structural reoccupation occurred among the early Palaeo-Eskimos, that activity area segregation was flexible, or that these people regularly cleaned out dwellings before reuse. However, actual studies addressing these issues are needed to explore the formation processes affecting these sites and, in this case, micro-debitage analysis would be particularly useful. While some of the studies addressed in this discussion use micro-refuse in their analyses of spatial use, the size of the particles they examine do vary (i.e. $2 \mathrm{~mm}$ to $6 \mathrm{~mm}$ ). This is largely because their research focuses on plant and faunal remains in addition to micro-debitage. In the context of the Pre-Dorset and other early Palaeo-Eskimo variants, I would advocate using Fladmark's (1982), and Baumler and Downum's (1989) definitions of microdebitage, which are particles $2 \mathrm{~mm}$ and smaller, that these micro-flakes really are less likely to be disturbed and/or re-deposited in secondary context.

There is one remaining caveat that does apply to all micro-debitage analyses regardless of culture area or site formation process: time. Collecting and processing soil samples for these studies is indeed efficient and easy to do; however, the time invested in identifying and counting micro-debitage flakes is extremely intensive. Simms and Heath (1990: 805) note that the time required to examine a 1 liter soil sample for traces of micro-refuse was anywhere from 2 hours to 80 hours. The analysis of the Area Q soil samples also required many hours. Despite this, the potential information that can be gained from this line of evidence makes the investment of time worthwhile, particularly when the only evidence preserved at a site consists of lithic artifacts. Moreover, the development of recognition software for various computer programs offers a way to help expedite the counting process, thus reducing the time required for analysis. By combining a core sampling strategy with micro-debitage analysis, Arctic archaeologists can take a more proactive approach to identify Pre-Dorset sites in their original contexts on southern Baffin Island. As such, we would not have to rely solely on the serendipitous discovery of isolated components, like Area Q, in order to learn about Pre-Dorset lifeways in this region. I believe this is where micro-debitage analysis can make the greatest contribution to Arctic research on the Pre-Dorset culture. 


\section{Conclusions}

The first objective of this paper was to describe the Area Q structure excavated at the Tungatsivvik site. Area Q provides important information about the Pre-Dorset culture in the Frobisher Bay region since it represents a rare isolated, undisturbed component. Pre-Dorset artifacts have been found in Thule structures excavated at Peale Point (Stenton 1983, 1987) and Davidson Point (Milne 1997; Park 1997) but where they came from in the larger site area remains unknown. Shaymark is another PreDorset component near Iqaluit; however, its disturbed context seriously compromises efforts to identify structural features and understand spatial use at the site. Area Q provides an example of a Pre-Dorset dwelling structure where separate activity areas can be inferred based on the distributions of both macro- and micro-debitage remains. The identification of micro-debitage in Area $Q$ is significant because it confirms its presence in Palaeo-Eskimo sites and demonstrates the ease with which it can be collected and processed.

The second objective of this paper was to address some of the challenges archaeologists encounter while investigating Pre-Dorset sites on southern Baffin Island. To help mitigate these challenges, I propose using micro-debitage analysis and a systematic core sampling strategy. While the applications I have discussed here are at present speculative in an Arctic context, micro-debitage analysis has been successfully used in site survey, activity area analysis, and for site verification purposes in British Columbia (Fladmark 1982), southern Alberta (Hull 1987; Oetelaar 2000), the American Southwest (Metcalf and Heath 1990; Simms and Heath 1990), Japan (Okazawa 1999), and Israel (Rosen 1989). I am confident that conducting micro-debitage analysis using soil core samples can contribute significantly to our present understanding of the PreDorset culture on southern Baffin Island, because it is an efficient way to identify sites and it enables the gathering of information from a large region with minimal expense. These techniques are of course applicable in other Arctic areas where multi-component sites, heavy vegetation cover, and preservation conditions are issues. If soil samples can be taken, micro-debitage analysis can be conducted.

\section{Acknowledgements:}

I would like to thank Aubrey Cannon for opening my eyes to the potential of micro-debitage analysis. Thank you to Robert Park for the opportunity to work on the Area Q component at Tungatsivvik, and for providing me access to study the lithic assemblage and soil samples. Thanks also to Sarah Bonesteel who worked with me on the Area Q component during the 1999 field season at Tungatsivvik. Aubrey Cannon, Robert Park, Sarah Bonesteel, Susan D. Milne, and two anonymous reviewers offered several helpful comments and suggestions on an earlier draft of this paper. Thank you to Eduard Reinhardt, Department of Geography and Geology, McMaster University, for the use of the microscopes in his lab. All of the soil samples examined in this study were processed in the Fisheries Archaeology Lab in the Department of Anthropology, McMaster University. Funding for this research was generously provided by the Social Sciences and Humanities Research Council of Canada Doctoral Fellowship Program, 
the Association of Canadian Universities for Northern Studies Studentship Awards Program, the Northern Scientific Training Program, and the McMaster University School of Graduate Studies. Funding to attend the conference in St. Pierre and Miquelon, where this paper was first presented, was provided by the Yates Scholarship Fund, McMaster University and the Department of Anthropology, McMaster University. Finally, many thanks to Sylvie LeBlanc and Murielle Nagy for organizing the conference in St. Pierre and Miquelon, and for inviting me to participate.

\section{References}

ANDREFSKY, William, Jr.

1998 Lithics: Macroscopic Approaches to Analysis, Cambridge, Cambridge University Press.

ARUNDALE, Wendy $\mathrm{H}$.

1981 Radiocarbon Dating in Eastern Arctic Archaeology: A Flexible Approach, American Antiquity, 46: 244-271.

BAUMLER, Mark F. and Christian E. DOWNUM

1989 Between Micro and Macro: A Study in the Interpretations of Small Sized Debitage, in D.S. Amick and R.P. Mauldin (eds), Experiments in Lithic Technology, Oxford, Archaeopress, BAR International Series, 528: 101116.

BINFORD, Lewis R.

1978a Nunamiut Ethnoarchaeology, New York, Academic Press.

1978b Dimensional Analysis of Behaviour and Site Structure: Learning from an Eskimo Hunting Stand, American Antiquity, 43(3): 330-361.

1979 Organization and Formation Processes: Looking at Curated Technologies, Journal of Anthropological Research, 35: 255-273.

1980 Willow Smoke and Dog Tails: Hunter-Gatherer Settlement Systems and Archaeological Site Formation, American Antiquity, 45(1): 4-20.

BONESTEEL, Sarah M.

2003 Gender Role Flexibility and Social Agency in Early Palaeoeskimo Archaeology, Paper Presented at the Canadian Archaeological Association Annual Meetings, McMaster University, Hamilton, Ontario, May 7-10, 2003.

BRADBURY, Andrew P. and Jay D. FRANKLIN

2000 Raw Material Variability, Package Size, and Mass Analysis, Lithic Technology, 25(1): 42-58 
CANNON, Aubrey

2000 Assessing Variability in Northwest Coast Salmon and Herring Fisheries: Bucket-Auger Sampling of Shell Midden Sites on the Central Coast of British Columbia, Journal of Archaeological Science, 27: 735-737.

CHATTERS, James C.

1987 Hunter-Gatherer Adaptations and Assemblage Structure, Journal of Anthropological Archaeology, 6: 336-375.

DEKIN, Albert A.

1976 Elliptical Analysis: An Heuristic Technique for the Analysis of Artifact Clusters, in M.S. Maxwell (ed.), Eastern Arctic Prehistory: Paleo-Eskimo Problems, Washington, Memoirs of the Society for American Archaeology, 31: 79-88.

DOBRES, Marcia-Anne

1995 Gender and Prehistoric Technology: On the Social Agency of Technical Strategies, World Archaeology, 27(1): 25-49.

FLADMARK, Knut R.

1982 Micro-Debitage Analysis: Initial Considerations, Journal of Archaeological Science, 9:205-220.

GOODYEAR, Albert C.

1993 Toolkit Entropy and Bipolar Reduction: A Study of Interassemblage Lithic Variability Among Paleo-Indian Sites in the Northeastern United States, North American Archaeologist, 14(1): 1-23.

GRØNNOW, Bjarne

1994 Qeqertasussuk - The Archaeology of a Frozen Saqqaq Site in Disko Bugt, West Greenland, in D. Morrison and J.-L. Pilon (eds), Threads in Arctic Prehistory: Papers in Honour of William E. Taylor, Jr., Hull, Canadian Museum of Civilization, Archaeological Survey of Canada, Mercury Series, 149: 197-238.

HAYDEN, Brian and Aubrey CANNON

1983 Where the Garbage Goes: Refuse Disposal in the Maya Highlands, Journal of Anthropological Archaeology, 2:117-163.

HULL, Kathleen

1987 Identification of Cultural Site Formation Processes Through Micro-debitage Analysis, American Antiquity, 52(4): 772-783.

JANES, Robert R.

1989 An Ethnoarchaeological Model for the Identification of Prehistoric Tepee Remains in the Boreal Forest, Arctic, 42(2): 128-138. 
McGHEE, Robert

1979 The Paleo-Eskimo Occupations at Port Refuge, High Arctic Canada, Ottawa, National Museum of Man, Archaeological Survey of Canada, Mercury Series, 92.

1990 Canadian Arctic Prehistory, Hull, Canadian Museum of Civilization.

1996 Ancient People of the Arctic, Vancouver, UBC Press.

MAXWELL, Moreau S.

1973 Archaeology of the Lake Harbour District, Baffin Island, Ottawa, National Museum of Man, Archaeological Survey of Canada, Mercury Series, 6.

1976 Pre-Dorset and Dorset Artifacts: The View From Lake Harbour, in M. S. Maxwell (ed.), Eastern Arctic Prehistory: Paleoeskimo Problems, Washington, Memoirs of the Society for American Archaeology, 31: 58-78.

1985 Prehistory of the Eastern Arctic, Orlando, Academic Press.

METCALF, Duncan and Kathleen M. HEATH

1990 Microrefuse and Site Structure: The Hearths and Floors of the Heartbreak Hotel, American Antiquity, 55(4):781-796.

MILNE, S. Brooke

1997 Lithic Analysis of the Paleo-Eskimo Component at the Thule Winter Site, KkDn-31, Baffin Island, NWT., unpublished undergraduate Honours thesis, Waterloo, University of Waterloo, Department of Anthropology.

2003 Peopling the Pre-Dorset Past: A Multi-Scalar Study of Early Arctic Lithic Technology and Seasonal Land Use Patterns on Southern Baffin Island, Ph.D. dissertation, Hamilton, McMaster University, Department of Anthropology.

MØBJERG, Tinna

1998 The Saqqaq Culture in the Sisimiut Municipality Elucidated by the Two Sites Nipisat and Asummiut, in J. Arneborg and H. C. Gulløv (eds), Man, Culture and the Environment in Ancient Greenland, Copenhagen, Danish Polar Center, Danish Polar Center Publication, 4: 98-118.

NELSON, Margaret C.

1991 The Study of Technological Organization, in M. Schiffer (ed.), Archaeological Method and Theory. Vol. 3, Tucson, The University of Arizona Press: 57-100.

ODELL, George H.

1994 Assessing Hunter-Gatherer Mobility in the Illinois Valley: Exploring Ambiguous Results, in P. J. Carr (ed.), The Organization of North American 
Prehistoric Chipped Stone Tool Technologies, Ann Arbor, Michigan, International Monographs in Prehistory, Archaeological Series, 7: 70-86.

OETELAAR, Gerald A.

2000 Beyond Activity Areas: Structure and Symbolism in the Organization and Use of Space Inside Tipis, Plains Anthropologist, 45(171): 35-61.

OKAZAWA, Sachiko

1999 Micro- and Macrodebitage Analysis in an Upper Palaeolithic Site of Japan, in L. R. Owen and M. Porr (eds), Ethno-Analogy and the Reconstruction of Prehistoric Artefact Use and Production, Tübingen, Mo-Vince-Verlog: 91101.

ORTON, Clive

$2000 \quad$ Sampling in Archaeology, Cambridge, University of Cambridge Press.

PARK, Robert W.

1997 Archaeological Investigations at Davidson Point, Baffin Island (Summer 1997), unpublished report on file, Yellowknife, Prince of Wales Northern Heritage Centre.

1998 Archaeological Investigations at the Tungatsivvik Site (KkDo-3), Baffin Island (Summer of 1998), unpublished report on file, Yellowknife, Prince of Wales Northern Heritage Centre.

1999 Archaeological Excavations at the Tungatsivvik Site (KkDo-3), Baffin Island (Summer 1999), unpublished report on file, Iqaluit, Department of Culture, Language, Elders, and Youth.

2001 Thule Winter Site Formation in Arctic Canada, Anthropological Papers of the University of Alaska (New Series), 1(1): 1-6.

RAMSDEN, Peter and Maribeth MURRAY

1995 Identifying Seasonality in Pre-Dorset Structures in Back Bay, Prince of Wales Island, N.W.T., Arctic Anthropology, 32(2): 106-117.

ROSEN, Arlene M.

1989 Ancient Town and City Sites: A View from the Microscope, American Antiquity, 54(3): 564-578.

SHOTT, Michael J.

1997 Activity and Formation as Sources of Variation in Great Lakes Paleo-Indian Assemblages, Midcontinental Journal of Archaeology, 22(2): 197-236.

1999 On Bipolar Reduction and Splintered Pieces, North American Archaeologist, 20(3): 217-238. 
SIMS, Steven R. and Kathleen M. HEATH

1990 Site Structure of the Orbit Inn: An Application of Ethnoarchaeology, American Antiquity, 55(4): 797-813.

SINCLAIR, Anthony

2000 Constellations of Knowledge: Human Agency and Material Affordance in Lithic Technology, in M. Dobres and J. Robb (eds), Agency and Archaeology, New York, Routledge: 196-212.

STENTON, Douglas R.

1983 An Analysis of Faunal Remains from the Peale Point site (KkDo-1), Baffin Island, N.W.T., M.A. thesis, Peterborough, Trent University, Department of Anthropology.

1987 Recent Archaeological Investigations in Frobisher Bay, Baffin Island, N.W.T., Canadian Journal of Archaeology, 11:13-48.

2001 Ideology and Site Formation Processes: An Example of Discard Behaviour from Baffin Island, Anthropological Papers of the University of Alaska (New Series), 1(1):13-22.

STENTON, Douglas R. and Bruce G. RIGBY

1995 Community-Based Heritage Education, Training and Research: Preliminary Report on the Tungatsivvik Archaeological Project, Arctic, 48(1): 47-56.

STENTON, Douglas R. and Robert W. PARK

1994 Formation Processes and Thule Archaeofaunas, in D. Morrison and J-L. Pilon (eds.), Threads of Arctic Prehistory: Papers in Honour of William E. Taylor, Jr., Hull, Canadian Museum of Civilization, Archaeological Survey of Canada, Mercury Series, 149: 409-422.

1998 Ancient Stone Tools of Nunavut: An Illustrated Guide, Ottawa, Parks Canada.

TOWNER, Ronald H. and Miranda WARBURTON

1990 Projectile Point Rejuvenation: A Technological Analysis, Journal of Field Archaeology, 17: 311-321.

VANCE, Elizabeth D.

1987 Micro-Debitage and Archaeological Activity Analysis, Archaeology, 40(4): 58-59. 